\title{
Communication \\ Core-Shell Iron-Nickel Hexacyanoferrate Nanoparticle-Based Sensors for Hydrogen Peroxide Scavenging Activity
}

\author{
Darya V. Vokhmyanina *(D), Elizaveta V. Shcherbacheva, Elena V. Daboss (D), Elena E. Karyakina \\ and Arkady A. Karyakin
}

check for updates

Citation: Vokhmyanina, D.V.; Shcherbacheva, E.V.; Daboss, E.V.; Karyakina, E.E.; Karyakin, A.A. Core-Shell Iron-Nickel Hexacyanoferrate NanoparticleBased Sensors for Hydrogen Peroxide Scavenging Activity. Chemosensors 2021, 9, 344. https://doi.org/ $10.3390 /$ chemosensors 9120344

Academic Editor: Khiena Z. Brainina

Received: 9 October 2021

Accepted: 3 December 2021

Published: 6 December 2021

Publisher's Note: MDPI stays neutral with regard to jurisdictional claims in published maps and institutional affiliations.

Copyright: (c) 2021 by the authors. Licensee MDPI, Basel, Switzerland. This article is an open access article distributed under the terms and conditions of the Creative Commons Attribution (CC BY) license (https:// creativecommons.org/licenses/by/ $4.0 /)$.
Chemistry Faculty, M.V. Lomonosov Moscow State University, 119991 Moscow, Russia; scherbacheva.e@gmail.com (E.V.S.); karpowa.ew@gmail.com (E.V.D.); ekaryakina@enzyme.chem.msu.ru (E.E.K.); aak@analyt.chem.msu.ru (A.A.K.)

* Correspondence: vokhmyanina@gmail.com

Abstract: To access hydrogen peroxide scavenging activity, we propose a sensor based on core-shell iron-nickel hexacyanoferrate nanoparticles. On the one hand, the sensor preparation procedure is simple: syringing the nanoparticles suspension with subsequent annealing. On the other hand, the sensor demonstrates a stable response to $0.05 \mathrm{mM}$ of $\mathrm{H}_{2} \mathrm{O}_{2}$ within one hour, which is sufficient for the evaluation of antioxidant activity (AO). The analytical performance characteristics of the sensor (0.5-0.6 $\mathrm{A} \mathrm{M}^{-1} \mathrm{~cm}^{-2}$, detection limit $1.5 \times 10^{-7} \mathrm{M}$ and linear dynamic range 1-1000 $\left.\mu \mathrm{M}\right)$ are leads to advantages over the sensor based on Prussian Blue films. The pseudo-first-order constant of hydrogen peroxide scavenging was chosen as a characteristic value of $\mathrm{AO}$. The latter for trolox (standard antioxidant) was found to be linearly dependent on its concentration, thus allowing for the evaluation of antioxidant activity in trolox equivalents. The approach was validated by analyzing real beverage samples. Both the simplicity of sensor preparation and an expressiveness of analytical procedure would obviously provide a wide use of the proposed approach in the evaluation of antioxidant activity.

Keywords: antioxidant activity; hydrogen peroxide scavenging; core-shell iron-nickel hexacyanoferrate nanoparticles

\section{Introduction}

Reactive oxygen species (ROS) serve to remove damaged macromolecules of proteins, lipids and other substances. However, an increased concentration of such substances can lead to a deviation from the redox balance. Oxidative stress caused by an imbalance of oxidants and reducers is one of the main risk factors for the development of cardiovascular [1], neurological [2], retinal [3], renal [4] and intestinal [5] diseases, takes part in diabetes [6], Alzheimer's disease [7] and cancer [8] and even affects aging [9,10]. The intake of reducing agents through food is believed to be one of the main ways to avoid those risks. An antioxidant can be defined as any substance that, when present in food or in the body at very low concentrations, delays, controls or prevents the initiation and propagation of oxidative stress [11].

Important antioxidants in food are vitamins (ascorbic acid, tocopherols), carotenoids (condensed tannins, xanthophylls and carotenes), flavonoids (flavones, isoflavines, flavonols, flavanols, flavanones), phenolic acids (hydroxyl-benzoic acid and hydroxyl-cinnamic acid) and phenolic alcohols [12]. For practical purposes knowing the total antioxidant activity (TAA) is required, regardless of the substances used. In addition, knowledge of the exact concentrations and activities of all components of the system does not provide complete knowledge of the TAA since the effect of the antioxidants is not additive (for example, synergism or antagonism is possible in such a system [13-16]).

Known methods for assessing the antioxidant activity can be divided into two groups. The first group of methods is based on the detection of an oxidizable product, e.g., a lipid 
oxidation product. The thiobarbituric acid reactive substances (TBARS) assay [17], as the most common method of this group, allows for the measurement of the ability of the antioxidant to prevent or enhance the effect of ROS on lipids. However, such methods are time consuming and require the use of a lipid substrate. Many factors (e.g., pre-formed peroxides in lipid) are implicated in the variability of both the formation of oxidation products and the antioxidant activity, complicating method standardization [18]. Therefore, methods based on the addition of oxidants to a specimen and the investigation of their further decomposition are of great interest.

Modern analytical techniques use radicals, metal compounds and even direct antioxidant electrooxidation. The use of natural radicals (such as the superoxide radical [19] and the hydroxide radical [20]) provides more reliable information about sample ability to scavenge ROS. However, the lifetime of natural radicals is negligible, requiring the introduction of a radical synthesis reaction into the system, thereby complicating the measurement procedure. The scavenging of artificial radicals method $[21,22]$ is simple, easy, economic, rapid and commonly employed for the evaluation of the radical scavenging activity of non-enzymatic antioxidants. The main disadvantage of using stable artificial radicals $\left(\mathrm{ABTS}^{+}, \mathrm{DPPH}\right.$, etc.) is their biological irrelevance, which does not reflect the situation in an oxidizing food or an in vivo situation [11]. Some methods using oxidizing agents $\left(\mathrm{Cl}_{2}, \mathrm{Br}_{2}, \mathrm{I}_{2}\right.$, ferric complexes, dichromate anion), which is convenient because such agents might be synthesized directly in the system, and much simpler and cheaper electrochemical equipment is required for both oxidant synthesis and TAA measurement by coulometric titration [23] or chronoamperometry [24]. However, these methods measure the concentration of the reducing agents in the sample rather than the antioxidant activity. The only sufficiently powerful and stable natural oxidizing agent is hydrogen peroxide. Although there is a chemiluminescence method for TAA measurement [25], that uses hydrogen peroxide as the oxidant, electrochemical assays seem to be more perspective.

Prussian Blue (PB) is known as a selective electrocatalyst for hydrogen peroxide reduction [26], which makes it a promising material for the fabrication of electrochemical $\mathrm{H}_{2} \mathrm{O}_{2}$ sensors. Despite its many advantages, it suffers from poor operational stability. Hence, the best way to develop an advanced electrocatalyst for $\mathrm{H}_{2} \mathrm{O}_{2}$ reduction with improved operational stability should be based on the stabilization of Prussian Blue. Various strategies have been used for this objective, for example, covering it with organic polymers [27], polyionomers [28] or multilayers of non-iron hexacyanoferrates [29-31] and entrapping it in sol-gel [32] or conductive polymer matrices [33]. However, despite the stabilization effect achieved, decreased catalytic activity was observed for the resulting materials. In addition, all of the developed techniques were time consuming, complicated and characterized by poor reproducibility.

In 2018 a new sensing material-Prussian Blue nanoparticles-was proposed by our research group [34]. PB nanoparticles can be prepared by chemical [34] or electrochemical [35] means and used to create improved sensors [36] and biosensors [37,38], whose performance characteristics are better compared to sensors based on Prussian Blue films. The only disadvantage of PB nanoparticles-low operational stability-was overcome in 2021 by performing catalytic synthesis on core-shell nanoparticles based on a PB core stabilized with a nickel hexacyanoferrate (NiHCF) shell [39].

We now propose sensors based on PB-NiHCF nanoparticles, which are characterized by high sensitivity and operational stability combined with a rapid and simple preparation technique for measuring antioxidant activity by monitoring of hydrogen peroxide scavenging.

\section{Materials and Methods}

\subsection{Reagents and Objects of Analysis}

Experiments were carried out with Millipore Milli-Q water. All inorganic salts and hydrogen peroxide ( $30 \%$ solution) were obtained at the highest purity from ReachIM (Moscow, Russia) and used as received. Samples of fruits and juices were bought in a local 
supermarket. Freshly squeezed juices were prepared immediately before the measurements and diluted two-fold with $0.1 \mathrm{M}$ of phosphate-buffered solution containing $0.2 \mathrm{M}$ of $\mathrm{KCl}$.

\subsection{Sensor Preparation}

Stabilized Prussian Blue (PB-NiHCF) nanoparticles were produced as described in [39]. Nanoparticles size distribution was estimated by dynamic light scattering using Malvern Zetasizer Nano ZS (Malvern Instruments Ltd., Malvern, UK). The Prussian Blue concentration in colloidal nanoparticles solution was determined spectrophotometrically $\left(\varepsilon_{700} \mathrm{~nm}\right.$ (per PB unit cell) $=4.85 \times 10^{4} \mathrm{M}^{-1} \cdot \mathrm{cm}^{-1}$ ). The obtained Prussian Blue nanoparticles were stored at $\mathrm{pH} 1.1$ and ultrasonicated prior to use. No changes in nanoparticles size or physicochemical properties were observed during 6 months of storage at room temperature. Screen-printed electrodes for hydrogen peroxide sensors manufacturing were obtained from RUSENS LTD (Moscow, Russia). The sensor contained a carbon auxiliary electrode surrounding the round working electrode $(\varnothing 1.8 \mathrm{~mm})$ modified with PB-NiHCF nanoparticles and an $\mathrm{Ag} \mid \mathrm{AgCl}$ reference electrode. The modification procedure was performed by placing a $2 \mu \mathrm{L}$ drop of a suspension containing PB or PB-NiHCF nanoparticles $(6.5 \mathrm{nM})$ onto the working electrode surface.

\subsection{Amperometric Measurements}

Monitoring of hydrogen peroxide with screen-printed sensors was carried out in batch mode upon stirring using PalmSens electrochemical interface (PalmSens BV, Houten, The Netherlands) interfaced to an IBM PC. A total of $0.05 \mathrm{M}$ of phosphate buffer containing $0.1 \mathrm{M}$ of $\mathrm{KCl}$ with a $\mathrm{pH}$ of 6.0 was used as supporting electrolyte in all experiments. The sensitivity was calculated as the tangent of initial response dependence on a concentration of hydrogen peroxide in the cell. The inactivation constant was determined as the slope of current decay in semi-logarithmic plots during long-term monitoring of $1 \mathrm{mM} \mathrm{of} \mathrm{H}_{2} \mathrm{O}_{2}$.

Measurements of antioxidant activity were performed in stirred solutions of food samples $(5 \mathrm{~mL})$ with an applied potential of $0 \mathrm{mV}$ vs. $\mathrm{Ag} \mid \mathrm{AgCl}$. A neutral $\mathrm{pH}$ of 6.0 was used as a compromise between physiological conditions (some physiological liquids, such as sweat, even have $\mathrm{pH} 6-7)$ and conditions suitable for sensor operation ( $\mathrm{pH}$ 1.0-6.0). Once a stable baseline current was reached (within 5-10 min), an aliquot of $\mathrm{H}_{2} \mathrm{O}_{2}$ solution $\left(2.5 \times 10^{-7} \mathrm{~mol}\right)$ was injected. After reaching the maximum response (within $\left.10 \mathrm{~s}\right)$ the kinetics of current decay was investigated. The concentration of hydrogen peroxide in stock solutions was controlled using the optical density at $230 \mathrm{~nm}$ with an LKB-Ultraspec UII spectrophotometer (Broma, Sweden).

\section{Results}

\subsection{Analytical Performances of PB-NiHCF Nanoparticle-Based Sensors for Hydrogen Peroxide}

The SEM image of the PB-NiHCF nanoparticle-modified electrodes (Figure S1c, Supplementary Materials) demonstrates the complete coating, which consists of smaller structure elements than PB film (Figure S1b, Supplementary Materials) on the carbon electrode surface (Figure S1a, Supplementary Materials). The presence of ferric and nickel hexacyanoferrates in the coating composition was confirmed by EDX spectrum (Figure S2, Supplementary Materials). The charge transfer resistance of the PB-NiHCF nanoparticle coating measured by electrochemical impedance spectroscopy was $5-10 \mathrm{Ohm} \cdot \mathrm{cm}^{-2}$ (Figure S3, Supplementary Materials) which corresponds to the same parameter of the PB nanoparticle coating [36].

The size distribution of the PB and PB-NiHCF nanoparticles was measured by the dynamic light-scattering method (Figure S4, Supplementary Materials). The analytical performances of nanoparticle-based hydrogen peroxide sensors strongly depend on their size. The sensitivity of sensors modified with the same amount of PB was decreased with increasing PB-NiHCF nanoparticle size (Figure S5, Supplementary Materials). The dependence of the inactivation constant was more complicated with a maximum of 66 $\mathrm{nm}$ (Figure S5, Supplementary Materials). In the core-shell particles used, the PB core 
provides hydrogen peroxide reduction electrocatalysis, whereas $\mathrm{NiHCFs}^{\prime}$ role is protecting PB through the solubilization under hydroxide anions - the main reason for nanoparticles' instability. As the PB nanoparticles that are identical in size were used as a core, this fact might be explained by the thicker nickel hexacyanoferrate shell formation, which protects the PB core from destruction but hinders the transport of hydrogen peroxide to the catalytically active core. For analytical applications, sensors with the maximum sensitivity (S) and minimum inactivation constant $\left(\mathrm{k}_{\mathrm{in}}\right)$ were used; therefore, the integral parameter $S \cdot \mathrm{k}_{\mathrm{in}}{ }^{-1}$ containing both parameters was proposed. Figure 1 demonstrates the integrated parameter dependence on nanoparticles' size. Nanoparticles with an average diameter of $43 \mathrm{~nm}$ were characterized by the optimum ratio of sensitivity to the inactivation constant among all other PB-NiHCF nanoparticles. The integrated parameter for pure PB nanoparticles is also shown on the graph for reference.

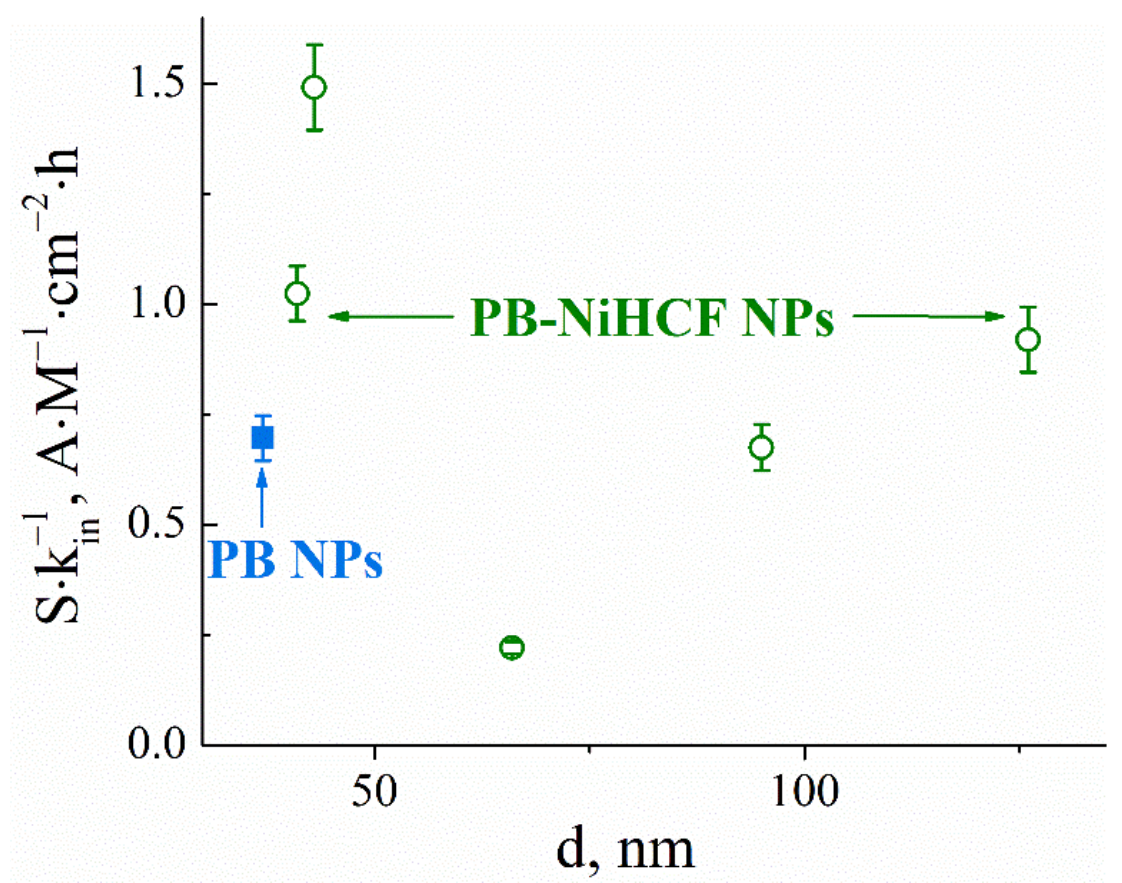

Figure 1. Integrated parameter based on sensitivity and inactivation constant for sensors based on PB-NiHCF nanoparticles with different sizes $(\bigcirc)$ and Prussian Blue nanoparticles $(\square)$.

The analytical performances of the resulting sensor in $\mathrm{H}_{2} \mathrm{O}_{2}$ detection were: sensitivity $0.5-0.6 \mathrm{~A} \mathrm{M}^{-1} \mathrm{~cm}^{-2}$, detection limit $1.5 \times 10^{-7} \mathrm{M}$ and linear dynamic range $1-1000 \mu \mathrm{M}$. The applicability of sensors based on PB-NiHCF nanoparticles for the continuous monitoring of the hydrogen peroxide concentration was investigated under the same conditions as for the measurement of antioxidant activity: phosphate-buffered solution $\mathrm{pH}$ 6.0, potential $0 \mathrm{mV}$ vs. $\mathrm{Ag} / \mathrm{AgCl}, 0.05 \mathrm{mM} \mathrm{H}_{2} \mathrm{O}_{2}$ under constant magnetic stirring.

Figure 2 demonstrates that sensors based on PB-NiHCF nanoparticles retain $>95 \%$ of the response for an hour, which is sufficient for further measurements. During the same time period, sensors based on PB nanoparticles lost more than $50 \%$ of the initial response. Simultaneously, stabilization had almost no effect on the value of the initial response. Thus, the developed sensors based on PB-NiHCF nanoparticles are a simple and efficient tool for monitoring hydrogen peroxide concentration. The main reason for the instability of Prussian Blue nanoparticles is their solubilization as a result of hydrogen peroxide reduction. In the absence of $\mathrm{H}_{2} \mathrm{O}_{2}$ there is no response, and there is no possible risk of harm to sensor sensitivity. 


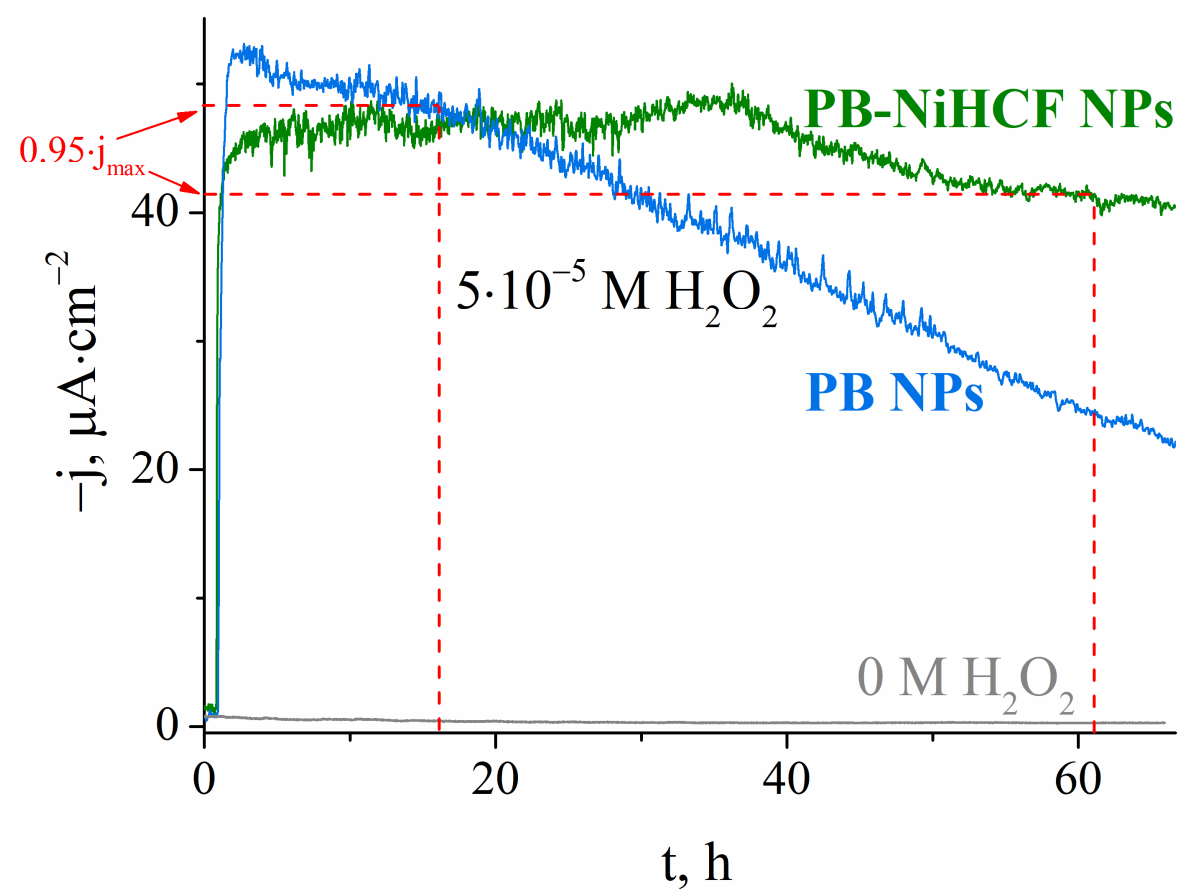

Figure 2. Operational stability of sensors based on PB-NiHCF nanoparticles (43 $\mathrm{nm}$ ) relative to sensors based on Prussian Blue nanoparticles $(37 \mathrm{~nm})$ in the absence and presence of $0.05 \mathrm{mM}$ of $\mathrm{H}_{2} \mathrm{O}_{2}, 0.1 \mathrm{M}$ of $\mathrm{KCl}, 0.05 \mathrm{M}$ of $\mathrm{KH}_{2} \mathrm{PO}_{4} / \mathrm{K}_{2} \mathrm{HPO}_{4}, \mathrm{pH} 6.0,0.0 \mathrm{~V}$ vs. $\mathrm{Ag} \mid \mathrm{AgCl}$.

\subsection{Hydrogen Peroxide Scavenging Assay as a Tool for Total Antioxidant Activity Evaluation}

The proposed new sensors based on PB-NiHCF nanoparticles were used to evaluate the total antioxidant activity in fresh and conservated juices. Figure 3a shows the constant decay of hydrogen peroxide concentration (proportional to cathodic current density) in fresh orange juice solution after its injection, whereas in commercial orange juice, $\mathrm{H}_{2} \mathrm{O}_{2}$ concentration remained stable, indicating low antioxidant activity.

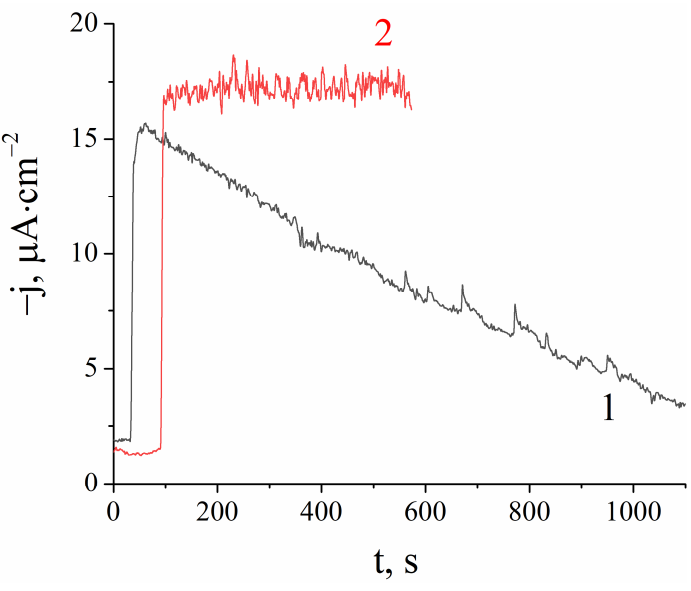

(a)

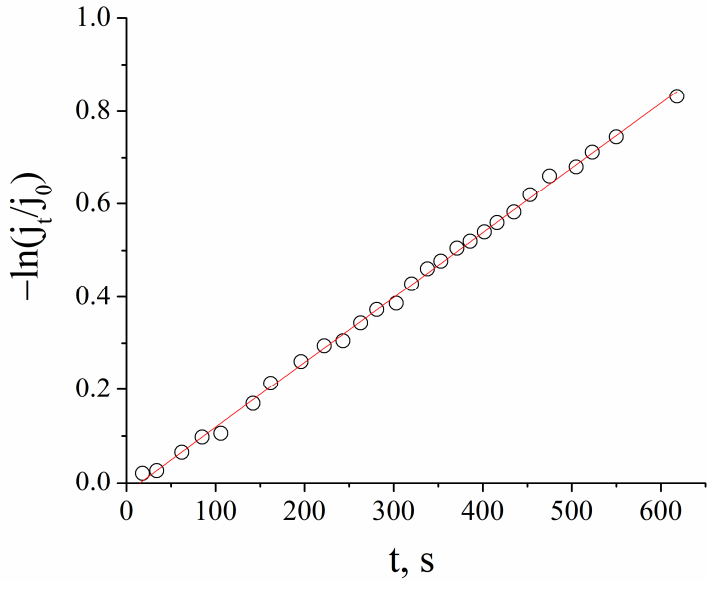

(b)

Figure 3. (a) Amperometric signal of hydrogen peroxide sensor after $\mathrm{H}_{2} \mathrm{O}_{2}$ injection in fresh orange juice (1) and orange juice "Dobryi" (2); (b) Relative (to peak current) current decay in semi-logarithmic plots (b) $(0.1 \mathrm{M} \mathrm{of} \mathrm{KCl}, 0.05 \mathrm{M}$ of $\mathrm{KH}_{2} \mathrm{PO}_{4} / \mathrm{K}_{2} \mathrm{HPO}_{4}, \mathrm{pH} 6.0,0.0 \mathrm{~V}$ vs. Ag | AgCl).

The reaction of $\mathrm{H}_{2} \mathrm{O}_{2}$ consumption in the presence of juice samples generally obeyed a pseudo-first-order kinetics equation. Figure $3 \mathrm{~b}$ shows the result of the data linearization in semi-logarithmic plots demonstrating good agreement between the experimental data and the calculated linearization curve. In the case of deviation from a straight line, an 
initial slope was considered. The kinetic constant $\mathrm{k}$ of hydrogen peroxide scavenging was determined from the slopes in semi-logarithmic plots. A higher kinetic constant indicates a more powerful antioxidant.

We investigated the possible interfering influence of system components on the sensor response. For that purpose, in addition to the regular experiment (in which hydrogen peroxide is added to the juice sample), we added $\mathrm{H}_{2} \mathrm{O}_{2}$ to the buffer solution, and juice sample was added $10 \mathrm{~min}$ after that (Figure S6, Supplementary Materials). In the absence of hydrogen peroxide, the sensor signal was close to zero and did not change. The initial point of the kinetic curve of hydrogen peroxide scavenging (after all reagents addition) was the same for both experiments. In presence of only $\mathrm{H}_{2} \mathrm{O}_{2}$, the response was twice higher because there was no two-fold dilution with juice sample. Thus, both the sensor incubation in real samples and the presence of real samples in the system do not affect sensor performances.

As a relative indicator of the total antioxidant activity of the samples Trolox, equivalents were used. In this way, comparison of the results with data obtained by other methods for assessing antioxidant activity becomes much easier, as the majority of them use trolox equivalents.

For this purpose, calculations of kinetic constants were made for trolox solutions in 1-10 mM (Figure S7, Supplementary Materials). According to the measurement results, the antioxidant activity of trolox was proportional to its concentration; the slope of the linear dependence was $0.093 \mathrm{M}^{-1} \cdot \mathrm{s}^{-1}$.

The results (in trolox equivalents) of TAA measurements in juices are shown in Table 1. For several juice samples, experiments were carried out using sensors modified with films of stabilized Prussian Blue [31] as well as sensors modified with the PB-NiHCF nanoparticles proposed in this work. Data comparison shows good agreement within the obtained results despite the different sensor material used. Thus, the results do not depend on the material of the hydrogen peroxide sensor used.

Table 1. Total antioxidant activity of juices.

\begin{tabular}{cc}
\hline Sample & c $_{\text {trolox }} \mathbf{~} \mathbf{m M}$ \\
\hline grapefruit, fresh (PB-NiHCF film) & $13 \pm 1$ \\
grapefruit, fresh (PB-NiHCF nanoparticles) & $12 \pm 1$ \\
orange, fresh (PB-NiHCF film) & $13 \pm 2$ \\
orange, fresh (PB-NiHCF nanoparticles) & $14 \pm 2$ \\
orange, "Ya" (PB-NiHCF film) & $2.9 \pm 0.3$ \\
orange, "Ya" (PB-NiHCF nanoparticles) & $3.2 \pm 0.3$ \\
orange, "J7" & $2.5 \pm 0.5$ \\
orange, "Bioitalia" & $4.7 \pm 0.3$ \\
orange, "Aushan" & $4.33 \pm 0.06$ \\
orange, "Dobryi" & $<0.1$ \\
birch sap, "Vkusvill" & $0.52 \pm 0.08$ \\
sea buckthorn, "Vkusvill" & $0.9 \pm 0.5$ \\
carrot, "Bioitalia" & $0.12 \pm 0.01$ \\
apple, "Aushan" & $0.9 \pm 0.3$ \\
black currant, "4 seasons" & $2.4 \pm 0.8$ \\
cranberry, "4 seasons" & $<0.1$ \\
cranberry, "Absolute nature" & $<0.1$ \\
\hline
\end{tabular}

The total antioxidant activity was found to differ by two orders of magnitude for different juice samples. Freshly squeezed grapefruit and orange juices were found to be more powerful antioxidants than the commercially available juices, as evidenced by the higher measured antioxidant activity. It appears that some antioxidants may be destroyed during conservation. Orange juices from different manufacturers also displayed significant differences in antioxidant activity; some of them even showed the absence of an ability to 
decompose hydrogen peroxide at all. The highest TAA was observed for citrus and black currant juices. On the contrary, cranberry juice had minor activity in peroxide elimination.

Despite the diversity of methods for TAA evaluation impeded by comparisons with other methods, we measured some of the samples with nonzero activity using an independent method based on electrogenerated $\mathrm{Br}_{2}$ as an oxidant. The total antioxidant activity of juices can be presented as a row: birch sap ("Vkusvill") $<$ black currant juice (" 4 seasons") $<$ orange juice ("J7") < orange juice ("Aushan") and < orange juice ("Ya"), which is in complete agreement with our data with Pearson's correlation coefficient of 0.85 . The antioxidant activity of freshly squeezed fruit juices was lower compared to commercial ones but in good agreement within the group (grapefruit TAA is $86 \%$ and $90 \%$ of orange TAA using our assay and independent one correspondingly). This fact can be explained by the presence of preservatives in commercial juices, which reduces agents, but not antioxidants, and leads to an overestimation of the signal measured by an independent method using the oxidizing agent- $\mathrm{Br}_{2}$.

Thus, the proposed method can be used for rapid TAA screening in food samples.

\section{Conclusions}

Cheap and express methods for the evaluation of antioxidant activity involve the use of oxidants, which are consumed in course of reaction with food components. Among possible oxidants, hydrogen peroxide is the most valuable. On the one hand, it is very powerful; the potential of its reduction into water is almost equal to that one of superoxide radical. However, in contrast to the latter, $\mathrm{H}_{2} \mathrm{O}_{2}$ is stable, which significantly simplifies the analytical procedure. On the other hand, unlike artificial oxidants, hydrogen peroxide presents in biological systems, thus making evaluated antioxidant activity more reliable.

The simple, cheap and reproducible preparation method and advanced exploitation characteristics turn the proposed sensor into an efficient tool for monitoring hydrogen peroxide scavenging. The simplicity and meaningfulness of the analytical procedure together with the usable sensor fabrication technique would obviously ensure a broad use of the developed approach in the evaluation of antioxidant activity.

Supplementary Materials: The following are available online at https: / www.mdpi.com/article/10 .3390 / chemosensors9120344/s1, Figure S1: SEM images of (a) bare carbon screen-printed electrode (SPE), (b) Prussian Blue film on SPE, (c) PB-NiHCF nanoparticles on SPE. The scalebar is $100 \mathrm{~nm}$, Figure S2: Energy dispersive X-ray (EDX) spectra of a PB-NiHCF nanoparticle-modified carbon screen-printed electrode, Figure S3: Impedance spectra in Niquist's plots of PB-NiHCF nanoparticles modified electrodes; $0.1 \mathrm{M}$ of $\mathrm{KCl}$ in $0.1 \mathrm{M}$ of $\mathrm{HCl}, \Delta \mathrm{E}=5 \mathrm{mV}, \mathrm{E}_{\mathrm{DC}}=120 \mathrm{mV}$ vs. $\mathrm{Ag} \mid \mathrm{AgCl}$ (Prussian Blue I Prussian White redox potential). Solid lines represent fitting to the equivalent circuit shown in the inset, Figure S4: Dynamic light-scattering fit for the log-normal distribution for Prussian Blue (-) and PB-NiHCF (- -) nanoparticles, Figure S5: Sensitivities $(\square, \star)$ and inactivation constants $(\bigcirc, \vec{j})$ for sensors based on PB-NiHCF nanoparticles and Prussian Blue nanoparticles, respectively ( $0.5 \mathrm{mM}$ of $\mathrm{H}_{2} \mathrm{O}_{2}, 0.1 \mathrm{M}$ of $\mathrm{KCl}, 0.05 \mathrm{M}$ of $\mathrm{KH}_{2} \mathrm{PO}_{4} / \mathrm{K}_{2} \mathrm{HPO}_{4}, \mathrm{pH} 6.0,0.0 \mathrm{~V}$ vs. Ag | $\mathrm{AgCl}$ ), FigureS6: Amperometric signal of hydrogen peroxide sensor after $\mathrm{H}_{2} \mathrm{O}_{2}$ injection in phosphatebuffered solution with consequent addition of fresh grapefruit juice (1) and after $\mathrm{H}_{2} \mathrm{O}_{2}$ injection in fresh grapefruit juice (2) $\left(0.1 \mathrm{M}\right.$ of $\mathrm{KCl}, 0.05 \mathrm{M}$ of $\mathrm{KH}_{2} \mathrm{PO}_{4} / \mathrm{K}_{2} \mathrm{HPO}_{4}, \mathrm{pH} 6.0,0.0 \mathrm{~V}$ vs. Ag | $\left.\mathrm{AgCl}\right)$, Figure S7: Dependence of antioxidant activity on trolox concentration $(0.1 \mathrm{M}$ of $\mathrm{KCl}, 0.05 \mathrm{M}$ of $\mathrm{KH}_{2} \mathrm{PO}_{4} / \mathrm{K}_{2} \mathrm{HPO}_{4}, \mathrm{pH}$ 6.0, $0.0 \mathrm{~V}$ vs. $\left.\mathrm{Ag} \mid \mathrm{AgCl}\right)$.

Author Contributions: Conceptualization, A.A.K. and E.E.K.; methodology, A.A.K., E.E.K. and D.V.V.; validation, D.V.V. and E.V.D.; formal analysis, D.V.V. and E.V.D.; investigation, E.V.S. and D.V.V.; resources, A.A.K.; data curation, D.V.V.; writing-original draft preparation, D.V.V. and A.A.K.; writing-review and editing, D.V.V., E.V.D. and A.A.K.; visualization, E.V.D., E.V.S. and D.V.V.; supervision, A.A.K.; project administration, D.V.V.; funding acquisition, A.A.K. All authors have read and agreed to the published version of the manuscript.

Funding: This research was funded by Russian Science Foundation, grant number 19-13-00131.

Data Availability Statement: Not applicable. 
Acknowledgments: The authors mourn the loss of Elena Karyakina. The memory of her will forever remain in the hearts of all friends, colleagues and students who knew and respected her.

Conflicts of Interest: The authors declare no conflict of interest.

\section{References}

1. Khurana, S.; Piche, M.; Hollingsworth, A.; Venkataraman, K.; Tai, T.C. Oxidative stress and cardiovascular health: Therapeutic potentialof polyphenols. Can. J. Physiol. Pharmacol. 2013, 91, 198-212. [CrossRef] [PubMed]

2. Carvalho, A.N.; Firuzi, O.; Gama, M.J.; van Horssen, J.; Saso, L. Oxidative Stress and Antioxidants in Neurological Diseases: Is There Still Hope? Curr. Drug Targets 2017, 18, 705-718. [CrossRef]

3. Castelli, V.; Paladini, A.; d'Angelo, M.; Allegretti, M.; Mantelli, F.; Brandolini, L.; Cocchiaro, P.; Cimini, A.; Varrass, G. Taurine and oxidative stress in retinal health and disease. CNS Neurosci. Ther. 2021, 27, 403-412. [CrossRef] [PubMed]

4. Ogura, Y.; Kitada, M.; Koya, D. Sirtuins and Renal Oxidative Stress. Antioxidants 2021, 10, 1198. [CrossRef]

5. Wang, Y.; Chen, Y.; Zhang, X.; Lu, Y.; Chen, H. New insights in intestinal oxidative stress damage and the health intervention effects of nutrients: A review. J. Funct. Foods 2020, 75, 104248. [CrossRef]

6. Perez-Matute, P.; Zulet, M.A.; Martinez, J.A. Reactive species and diabetes: Counteracting oxidative stress to improve health. Curr. Opin. Pharmacol. 2009, 9, 771-779. [CrossRef]

7. Reddy, V.P.; Zhu, X.; Perry, G.; Smith, M.A. Oxidative Stress in Diabetes and Alzheimer's Disease. J. Alzheimers Dis. 2009, 16, 763-774. [CrossRef]

8. Klaunig, J.E. Oxidative Stress and Cancer. Curr. Pharm. Des. 2018, 24, 4771-4778. [CrossRef]

9. Salmon, A.B.; Richardson, A.; Pérez, V.I. Update on the oxidative stress theory of aging: Does oxidative stress play a role in aging or healthy aging? Free Radic. Biol. Med. 2010, 48, 642-655.

10. Hughes, M.; Williams, G.; Pageon, H.; Fourtanier, A.; Green, A. Dietary Antioxidant Capacity and Skin Photoaging: A 15-Year Longitudinal Study. J. Investig. Dermatol. 2021, 141, 1111-1118. [CrossRef] [PubMed]

11. Shahidi, F.; Zhong, Y. Measurement of antioxidant activity. J. Funct. Foods 2015, 18, 757-781. [CrossRef]

12. Comert, E.D.; Gokmen, V. Evolution of food antioxidants as a core topic of food science for a century. Food Res. Int. 2018, 105, 76-93. [CrossRef]

13. Ohkatsu, Y.; Suzuki, F. Synergism between Phenolic Antioxidants in Autoxidation. J. Jpn. Petrol. Inst. 2011, 54, 22-29. [CrossRef]

14. Pereira, R.B.; Sousa, C.; Costa, A.; Andrade, P.B.; Valentao, P. Glutathione and the Antioxidant Potential of Binary Mixtures with Flavonoids: Synergisms and Antagonisms. Molecules 2013, 18, 8858-8872. [CrossRef]

15. Celik, E.E.; Gokmen, V.; Skibsted, L.H. Synergism between Soluble and Dietary Fiber Bound Antioxidants. J. Agric. Food Chem. 2015, 63, 2338-2343. [CrossRef] [PubMed]

16. Sazhina, N.; Plotnikov, E.; Korotkova, E.; Dorozhko, E.; Voronova, O. Electrochemical Oxidability of Antioxidants: Synergism and Antagonism in Mixes. J. Pharm. Bioallied Sci. 2018, 10, 60-65.

17. Ghani, M.A.; Barril, C.; Bedgood, D.R., Jr.; Prenzler, P.D. Measurement of antioxidant activity with the thiobarbituric acid reactive substances assay. Food Chem. 2017, 230, 195-207. [CrossRef]

18. Ghani, M.A.; Barril, C.; Bedgood, D.R., Jr.; Prenzler, P.D. Substrate and TBARS variability in a multi-phase oxidation system. Eur. J. Lipid Sci. Technol. 2017, 119, 1500500. [CrossRef]

19. Juárez-Gómez, J.; Ramírez-Silva, M.T.; Guzmán-Hernández, D.S.; Romero-Romo, M.; Palomar-Pardavé, M. Novel electrochemical method to evaluate the antioxidant capacity of infusions and beverages, based on in situ formation of free superoxide radicals. Food Chem. 2020, 332, 127409. [CrossRef]

20. Prior, R.L.; Wu, X.; Schaich, K. Standardized Methods for the Determination of Antioxidant Capacity and Phenolics in Foods and Dietary Supplements. J. Agric. Food Chem. 2005, 53, 4290-4302.

21. Ilyasov, I.R.; Beloborodov, B.L.; Selivanova, I.A.; Terekhov, R.P. ABTS/PP Decolorization Assay of Antioxidant Capacity Reaction Pathways. Int. J. Mol. Sci. 2020, 21, 1131. [CrossRef] [PubMed]

22. Sharma, O.P.; Bhat, T.K. DPPH antioxidant assay revisited. Food Chem. 2009, 113, 1202-1205. [CrossRef]

23. Ziyatdinova, G.; Salikhova, I.; Budnikov, H. Coulometric titration with electrogenerated oxidants as a tool for evaluation of cognac and brandy antioxidant properties. Food Chem. 2014, 150, 80-86. [CrossRef] [PubMed]

24. Brainina, K.Z.; Varzakova, D.P.; Gerasimova, E.L. A chronoamperometric method for determining total antioxidant activity. J. Anal. Chem. 2012, 67, 364-369. [CrossRef]

25. Papadopoulos, K.; Triantis, T.; Yannakopoulou, E.; Nikokavoura, A.; Dimotikali, D. Comparative studies on the antioxidant activity of aqueous extracts of olive oils and seed oils using chemiluminescence. Anal. Chim. Acta 2003, 494, 41-47. [CrossRef]

26. Karyakin, A.A. Advances of Prussian blue and its analogues in (bio)sensors. Curr. Opin. Electrochem. 2017, 5, 92-98. [CrossRef]

27. Lukachova, L.V.; Kotel'nikova, E.A.; D’Ottavi, D.; Shkerin, E.A.; Karyakina, E.E.; Moscone, D.; Palleschi, G.; Curulli, A.; Karyakin, A.A. Nonconducting Polymers on Prussian Blue Modified Electrodes: Improvement of Selectivity and Stability of the Advanced $\mathrm{H}_{2} \mathrm{O}_{2}$ Transducer. IEEE Sens. J. 2003, 3, 326-332. [CrossRef]

28. Karyakina, E.E.; Vokhmyanina, D.V.; Sizova, N.V.; Sabitov, A.N.; Borisova, A.V.; Sazontova, T.G.; Arkhipenko, Y.V.; Tkachuk, V.A.; Zolotov, Y.A.; Karyakin, A.A. Kinetic approach for evaluation of total antioxidant activity. Talanta 2009, 80, 749-753. [CrossRef]

29. Sitnikova, N.A.; Borisova, A.V.; Komkova, M.A.; Karyakin, A.A. Superstable Advanced Hydrogen Peroxide Transducer Based on Transition Metal Hexacyanoferrates. Anal. Chem. 2011, 83, 2359-2363. [CrossRef] 
30. Sitnikova, N.A.; Komkova, M.A.; Khomyakova, I.V.; Karyakina, E.E.; Karyakin, A.A. Transition Metal Hexacyanoferrates in Electrocatalysis of $\mathrm{H}_{2} \mathrm{O}_{2}$ Reduction: An Exclusive Property of Prussian Blue. Anal. Chem. 2014, 86, 4131-4134. [CrossRef]

31. Karpova, E.V.; Karyakina, E.E.; Karyakin, A.A. Iron-nickel hexacyanoferrate bilayer as an advanced electrocatalyst for $\mathrm{H}_{2} \mathrm{O}_{2}$ reduction. RSC Adv. 2016, 6, 103328-103331. [CrossRef]

32. Salimi, A.; Abdi, K. Enhancement of the analytical properties and catalytic activity of a nickel hexacyanoferrate modified carbon ceramic electrode prepared by two-step sol-gel technique: Application to amperometric detection of hydrazine and hydroxyl amine. Talanta 2004, 63, 475-483. [CrossRef]

33. Borisova, A.V.; Karyakina, E.E.; Cosnier, S.; Karyakin, A.A. Current-Free Deposition of Prussian Blue with Organic Polymers: Towards Improved Stability and Mass Production of the Advanced Hydrogen Peroxide Transducer. Electroanalysis 2009, 21, 409-414. [CrossRef]

34. Komkova, M.A.; Karyakina, E.E.; Karyakin, A.A. Catalytically synthesized Prussian Blue nanoparticles defeating natural enzyme peroxidase. J. Am. Chem. Soc. 2018, 140, 11302-11307. [CrossRef]

35. Komkova, M.A.; Vetoshev, K.R.; Andreev, E.A.; Karyakin, A.A. Flow-electrochemical synthesis of Prussian Blue based nanozyme 'artificial peroxidase'. Dalton Trans. 2021, 50, 11385-11389. [CrossRef]

36. Komkova, M.A.; Zarochintsev, A.A.; Karyakina, E.E.; Karyakin, A.A. Electrochemical and sensing properties of Prussian Blue based nanozymes "artificial peroxidase". J. Electroanal. Chem. 2020, 872, 114048. [CrossRef]

37. Vokhmyanina, D.V.; Andreeva, K.D.; Komkova, M.A.; Karyakina, E.E.; Karyakin, A.A. 'Artificial peroxidase' nanozyme-Enzyme based lactate biosensor. Talanta 2020, 208, 120393. [CrossRef] [PubMed]

38. Komkova, M.A.; Andreeva, K.D.; Zarochintsev, A.A.; Karyakin, A.A. Nanozymes 'Artificial Peroxidase'—Enzymes Oxidases Mixtures for Single-Step Fabrication of Advanced Electrochemical Biosensors. ChemElectroChem 2021, 8, 1117-1122. [CrossRef]

39. Karpova, E.V.; Shcherbacheva, E.V.; Komkova, M.A.; Eliseev, A.A.; Karyakin, A.A. Core-Shell Nanozymes "Artificial Peroxidase": Stability with Superior Catalytic Properties. J. Phys. Chem. Lett. 2021, 12, 5547-5551. [CrossRef] 